\title{
Endoscopy during the peak of COVID-19 pandemic: impact on activity and financial implications for a tertiary referral center in London
}

\author{
Alberto Murino ${ }^{a}$, Rocio Chacchi Cahuin ${ }^{a}$, Leonardo Franzoni ${ }^{b}$, Nikolaos Lazaridisa ${ }^{a}$ Alexandros Skamnelos ${ }^{a}$, \\ Jonathan Potts ${ }^{a}$, Lorenzo Fucciob, Charles D. Murray ${ }^{a}$, Douglas Thorburn ${ }^{a}$, Edward J. Despott ${ }^{\mathrm{a}}$
}

Royal Free Unit for Endoscopy, The Royal Free Hospital and University College London Institute for Liver and Digestive Health, Hampstead, London, UK; DIMEC, University of Bologna, Italy

\section{Abstract}

\begin{abstract}
Background COVID-19 pandemic is an unprecedented global medical emergency. National and international gastrointestinal societies recommended that any endoscopic activity during the lockdown phase of the pandemic should be limited to emergency or non-deferrable procedures only. We assessed the financial implications and impact on endoscopy activity of the lockdown phase in a tertiary referral endoscopy unit.
\end{abstract}

Methods The number of endoscopy procedures canceled and performed in our endoscopy unit during our "delay phase" (16-22/03/2020) and "lockdown phase" (23/03-29/05/2020) was reviewed and compared with endoscopy activity conducted during the same period in 2019. The financial impact was subsequently analyzed.

Results Between 16/03/2020 and 29/05/2020, 683 procedures were canceled and 365 nondeferrable procedures were performed. In contrast, in 2019, 3437 procedures were performed over the same timeframe, resulting in a revenue contraction of approximately $€ 2,062,857$. We estimated that the number of lists required to recuperate the canceled endoscopic activity, ranges from 103-155, depending on the level of personal protective equipment required and mitigating policy relating to COVID-19.

Conclusion Our results highlight that COVID-19 pandemic had a substantial negative impact on our endoscopy activity and on the revenue generated by our endoscopy unit.

Keywords COVID-19 pandemic, financial implications, endoscopy impact, endoscopic activity, endoscopy department

Ann Gastroenterol 2021; 34 (1): 1-7
${ }^{a}$ Royal Free Unit for Endoscopy, The Royal Free Hospital and University College London Institute for Liver and Digestive Health, Hampstead, London, UK (Alberto Murino, Rocio Chacchi Cahuin, Nikolaos Lazaridis, Alexandros Skamnelos, Jonathan Potts, Charles D. Murray, Douglas Thorburn, Edward J. Despott); ${ }^{b}$ Department of Medical and Surgical Sciences DIMEC, University of Bologna, Italy (Leonardo Franzoni, Lorenzo Fuccio)

Conflict of Interest: Alberto Murino has acted as a consultant for Boston Scientific and GI supply; he has also received academic grants from Fujifilm, Aquilant Endoscopy, Norgine and Olympus. Edward J. Despott has acted as a consultant for Boston Scientific and Ambu. He has also received academic grants and speaker honoraria from Fujifilm, Aquilant Endoscopy, Norgine and Olympus. The rest of the authors have declared no conflict of interest

Correspondence to: Alberto Murino MD, Royal Free Unit for Endoscopy, The Royal Free Hospital and University College London (UCL), Pond Street, London NW3 2QG, UK,

e-mail: a.murino@ucl.ac.uk

Received 6 February 2021; accepted 14 April 2021; published online 2 July 2021

DOI: https://doi.org/10.20524/aog.2021.0651

\section{Introduction}

COVID-19 is a highly infectious disease caused by the newly discovered SARS-CoV-2 [1], which in just a few months since its outbreak has precipitated a $21^{\text {st }}$ century pandemic of unforeseen proportions [2,3]. Most cases of COVID-19 (up to 88\%) appear to be asymptomatic, augmenting its rapid spread $[4,5]$. Symptoms most commonly include fever, lethargy, cough, dyspnea, and diarrhea $[1,6,7]$. Hospitalization rates appear to be dependent on age, sex, associated comorbidities and ethnic background, ranging from $1-20 \%$ in patients $\leq 30$ and $\geq 80$ years of age, respectively [8]. The main adverse outcomes of COVID-19 infection are precipitated by a severe viral pneumonitis, which in turn may lead to direct respiratory failure, acute respiratory distress syndrome, pro-thrombotic coagulation dysfunction, secondary sepsis, refractory metabolic acidosis, and eventual multiorgan failure with a fatality rate of up to $3.5 \%[2,3,9]$.

COVID-19 infection appears to be transmitted through droplets or aerosolization of respiratory secretions and contaminated environmental surfaces (fomites) [10,11]; viral shedding in feces is also described [12]. Virions can be 
detected for up to $3 \mathrm{~h}$ after aerosolization and up to 3-4 days on surfaces [13]. Upper gastrointestinal (GI) endoscopy procedures are recognized to be aerosol-generating procedures (AGP) and endoscopy staff are therefore considered to be also at an increased risk of infection through this route [1,4,6,14-16]. During lower GI endoscopic procedures, transmission to staff could also potentially occur through inadvertent contact/splashing with contaminated fecal droplets [12]. For this reason, national and international GI societies/organizations issued rapid guidelines [15-18] during the pandemic peak. The main universal recommendation was for endoscopy services to strictly limit their activity to emergency or non-deferrable procedures, while postponing all elective and non-urgent endoscopic procedures $[15,16]$. The rationale behind these recommendations was: (i) to decrease the potential risk of infection to both patients and staff [19]; and (ii) to allow redeployment of both medical and nursing members of the endoscopy team to areas of the institution where they were needed most-i.e., for the care of the everincreasing number of inpatients with COVID-19 infection on our wards and in the intensive care unit (ICU).

In this unprecedented situation, little is known about the scale of the impact on activity and financial revenue of these necessary measures on the provision of services delivered by endoscopy units. The aim of our study was to assess the impact of these mitigating measures applied during the COVID-19 pandemic peak on a busy tertiary referral endoscopy unit in London.

\section{Patients and methods}

As the number of COVID-19 cases increased rapidly across Europe, following theinitialdevastating consequencesin northern Italy and Spain, the government of the United Kingdom (UK) had initially responded with a four-step strategy: contain, delay, research and mitigate [20]. The "delay phase" was introduced on March 12, 2020 [21]. At that point, large gatherings were suspended, while social-distancing measures and hand-hygiene recommendations were widely encouraged through a massive social- and traditional mass-media national campaign. In line with the UK Government's strategy and associated guidance from the British Society of Gastroenterology (BSG), on March 16, 2020, our department canceled any non-urgent elective procedures. We refer to this period as our "delay phase".

On March 23, 2020, the UK government rapidly shifted its strategy to a national lockdown [22,23]. Consequently, and in congruence with synchronously updated guidance from the BSG, our department immediately canceled all elective procedures and shifted to the exclusive provision of an emergency endoscopy service. We shall refer to the period from March 23 to May 29 as the "lockdown phase". The "lockdown phase" finally ended on June 1, when our department restarted booking outpatients' elective endoscopic procedures.

Our institution is a large teaching hospital in north-central London, with a catchment population of about 600,000. Our endoscopy unit caters for tertiary referral advanced endoscopy, as well as routine diagnostic and therapeutic work for outpatients and inpatients. Our usual practice is to run a workload of an average of 4 rooms to capacity (of up to 12 points on each list, where 1 point is a 15 -min timeslot) (Table 1 ), with morning and afternoon sessions from Monday to Friday. "Extra" all-day lists are run in 3 rooms over the weekend, in order to keep abreast with our waiting list. For the purposes of this study, we reviewed the number of endoscopy procedures canceled and performed between March 16 and May 29. Patient demographics, procedure indication, inpatient/outpatient status, procedure urgency and diagnosis were analyzed. Our comparative control and measure of typical endoscopy activity was obtained through a similar review of all endoscopy procedures performed in our unit during the same timeframe in 2019.

Since the risk of COVID-19 infection would persist even after elective work resumption [24], we further hypothesized 3 situations: (i) that endoscopic activity would take the same time as before the COVID-19 pandemic (following standard safety precautions); (ii) that endoscopic activity would take approximately 25\% longer than before (following enhanced precautions with full personal protective equipment (PPE) but rapid turnover of outpatients; and (iii) that endoscopic activity would take approximately 50\% longer (following maximum precautions with full PPE and less rapid turnover of outpatients, because of isolation of patients with confirmed COVID-19) [24].

The financial implications of these cancelations on our endoscopic unit were estimated with reference to the 2019/2020 National Tariff Payment System [25], an official set of coded tariffs established by the National Health Service for care providers and commissioners. We calculated the revenue loss during the delay and lockdown phases and compared it with the same period in 2019 .

\section{Results}

\section{Endoscopy activity}

During the "delay phase" (between March 16 and 22, 2020), 213 non-urgent endoscopic procedures planned

Table 1 Estimated number of procedures per endoscopic list (based on a 12-point list, where 1 point represents a 15 -min timeslot)

\begin{tabular}{lc}
\hline Procedure type & $\begin{array}{c}\text { No. of procedures } \\
\text { per list }\end{array}$ \\
\hline Colonoscopy & 6 \\
Esophago-gastro-duodenoscopy (EGD) & 12 \\
$\begin{array}{l}\text { Sigmoidoscopy } \\
\text { Therapeutic colonoscopy, EGD, or } \\
\text { sigmoidoscopy }\end{array}$ & 12 \\
$\begin{array}{l}\text { Endoscopic retrograde } \\
\text { cholangiopancreatography }\end{array}$ & 3 \\
Endoscopic ultrasound & 4 \\
Capsule endoscopy & 4 \\
Double-balloon enteroscopy & 5 \\
\hline
\end{tabular}


for 197 patients were canceled (Table 2). During this same period, 93 procedures were performed on the same number of patients (44 men, median age 60.7 years; 23 inpatients and 70 outpatients) (Table 3).

During the "lockdown phase", 470 endoscopic procedures were canceled for 442 patients (Table 2), while 272 procedures were performed in the same number of patients (Table 3 ). When the data from both "phases" were combined, we found that a total of 683 procedures were canceled and only 365 procedures were performed.

Over the same period in 2019 (Table 4), 3437 endoscopic procedures were performed in total, i.e., 3072 more procedures when compared with those performed during the same timeframe in 2020. For the "lockdown phase" this translated into a reduction by 2935 procedures in 2020 as compared with the same period in 2019 (Fig. 1).

In addition, since the risk of COVID-19 infection would persist after the resolution of the peak, we further estimated that the the number of endoscopic lists required to recuperate the canceled procedures during the delay and lockdown phase would be 103 (i), 129 (ii) and 155 (iii), for the 3 correspondingly numbered scenarios described in the Methods section above [24].

\section{Financial implications}

Based on our comparative estimate (using the 2019/2020 National Tariff Payment System [25] as a reference), during the "delay phase" our endoscopy unit suffered a loss of $€ 162,068$ in potential revenue, as a result of the cancelation of all non-urgent procedures. During the "lockdown phase", the estimated loss of revenue caused by cancelations was around $€ 413,808$ (Table 2).

When the estimated revenues from 2019 and 2020 (Tables 3, 4) were compared, a contraction of $€ 94,628$ was seen related to the "delay phase" and $€ 1,968,229$ related to the "lockdown phase". The overall income generated by endoscopy activity for both "phases" combined (i.e., from March 16 to May 29, 2020) was reduced by $€ 2,062,857$ when compared to that generated during the same period in 2019 (Fig. 2).

In our endoscopy unit all the procedures were performed using full PPE (e.g. gowns, gloves, aprons, face shields, caps and surgical masks) (Fig. 3,4). It should be noted that all additional

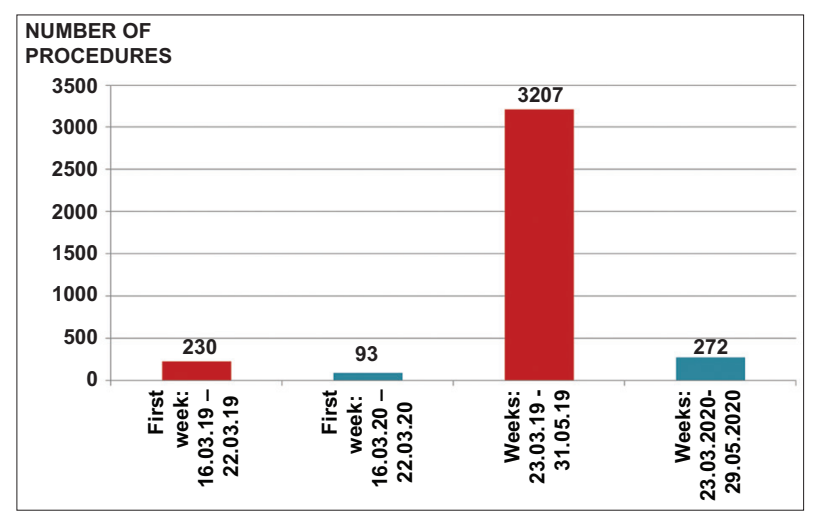

Figure 1 Number of endoscopy procedures performed during the delay and lockdown phases compared to the same period in 2019

Table 2 Procedures canceled from March 16 to May 29, 2020, and potential revenue impact

\begin{tabular}{|c|c|c|c|c|c|}
\hline Type of procedure & $\begin{array}{c}\text { Tariff } \\
(€)\end{array}$ & $\begin{array}{l}\text { Procedures canceled } \\
\text { during "delay phase" }\end{array}$ & $\begin{array}{c}\text { "Delay phase" } \\
\text { financial loss }(€)\end{array}$ & $\begin{array}{c}\text { Procedures canceled } \\
\text { during "lockdown phase" }\end{array}$ & $\begin{array}{l}\text { "Lockdown phase" } \\
\text { financial loss }(€)\end{array}$ \\
\hline \multicolumn{6}{|l|}{ Colonoscopy } \\
\hline Diagnostic & 710 & 58 & 41,180 & 154 & 109,340 \\
\hline Therapeutic & 794 & 2 & 1588 & 11 & 8734 \\
\hline \multicolumn{6}{|l|}{ Gastroscopy } \\
\hline Diagnostic & 547 & 92 & 50,324 & 170 & 92,990 \\
\hline Therapeutic & 702 & 1 & 702 & 4 & 2808 \\
\hline \multicolumn{6}{|l|}{ Sigmoidoscopy } \\
\hline Diagnostic & 531 & 25 & 13,275 & 40 & 21,240 \\
\hline Therapeutic & 603 & 6 & 3618 & 8 & 4824 \\
\hline \multicolumn{6}{|l|}{ ERCP } \\
\hline Diagnostic & 1124 & 1 & 1124 & 0 & 0 \\
\hline Therapeutic & 3136 & 12 & 37,632 & 36 & 112,896 \\
\hline \multicolumn{6}{|l|}{ EUS } \\
\hline Diagnostic & 839 & 7 & 5873 & 16 & 13,424 \\
\hline Capsule endoscopy & 1104 & 5 & 5520 & 24 & 26,496 \\
\hline DBE & 3008 & 4 & 1232 & 7 & 21,056 \\
\hline Total & & 213 & 162,068 & 470 & 413,808 \\
\hline
\end{tabular}

DBE, double-balloon enteroscopy; ERCP, endoscopic retrograde cholangiopancreatography; EUS, endoscopic ultrasound 
4 A. Murino et al

Table 3 Revenue from procedures performed from March 16 to May 29, 2020

\begin{tabular}{|c|c|c|c|c|c|}
\hline Type of procedure & $\begin{array}{c}\text { Tariff } \\
(€)\end{array}$ & $\begin{array}{l}\text { Procedures performed } \\
\text { during "delay phase" }\end{array}$ & $\begin{array}{l}\text { Financial gain from } \\
\text { "delay phase" }(€)\end{array}$ & $\begin{array}{l}\text { Procedures performed } \\
\text { during "lockdown phase" }\end{array}$ & $\begin{array}{l}\text { Financial gain from } \\
\text { "lockdown phase" }(€)\end{array}$ \\
\hline \multicolumn{6}{|l|}{ Colonoscopy } \\
\hline Diagnostic & 710 & 11 & 7810 & 11 & 7810 \\
\hline Therapeutic & 794 & 5 & 3970 & 8 & 6,352 \\
\hline \multicolumn{6}{|l|}{ Gastroscopy } \\
\hline Diagnostic & 547 & 24 & 13,128 & 82 & 44,854 \\
\hline Therapeutic & 702 & 6 & 4212 & 44 & 30,888 \\
\hline \multicolumn{6}{|l|}{ Sigmoidoscopy } \\
\hline Diagnostic & 531 & 12 & 6372 & 21 & 11,151 \\
\hline Therapeutic & 603 & 3 & 1809 & 4 & 2412 \\
\hline \multicolumn{6}{|l|}{ ERCP } \\
\hline Therapeutic & 3,136 & 14 & 43,904 & 69 & 216,384 \\
\hline Diagnostic & 1,124 & 2 & 2248 & 4 & 4496 \\
\hline \multicolumn{6}{|l|}{ EUS } \\
\hline Diagnostic & 839 & 8 & 6712 & 25 & 20,975 \\
\hline Therapeutic & 839 & 1 & 839 & 1 & 839 \\
\hline Capsule endoscopy & 1,104 & 6 & 6624 & 0 & 0 \\
\hline DBE & 3,008 & 1 & 3008 & 3 & 9024 \\
\hline Total & & 93 & 100,636 & 272 & 355,185 \\
\hline
\end{tabular}

DBE, double-balloon enteroscopy; ERCP, endoscopic retrograde cholangiopancreatography; EUS, endoscopic ultrasound

Table 4 Revenue from procedures performed from $16^{\text {th }}$ of March to $29^{\text {th }}$ of May 2019

\begin{tabular}{|c|c|c|c|c|c|}
\hline Type of procedure & $\begin{array}{c}\text { Tariff } \\
(€)\end{array}$ & $\begin{array}{c}\text { Procedures } \\
\text { performed from } \\
\text { March } 16 \text { to } 22,2020\end{array}$ & $\begin{array}{l}\text { Financial gain } \\
\text { from March } 16 \\
\text { to } 22,2020(€)\end{array}$ & $\begin{array}{l}\text { Procedures performed } \\
\text { from March } 23 \text { to } \\
\text { May 29, } 2020\end{array}$ & $\begin{array}{l}\text { Financial gain } \\
\text { from March } 23 \text { to } \\
\text { May } 29,2020(€)\end{array}$ \\
\hline \multicolumn{6}{|l|}{ Colonoscopy } \\
\hline Diagnostic & 710 & 60 & 42,600 & 981 & 696,510 \\
\hline Therapeutic & 794 & 12 & 9528 & 214 & 169,916 \\
\hline \multicolumn{6}{|l|}{ Gastroscopy } \\
\hline Diagnostic & 547 & 100 & 54,700 & 1,474 & 806,278 \\
\hline Therapeutic & 702 & 3 & 2106 & 38 & 26,676 \\
\hline \multicolumn{6}{|l|}{ Sigmoidoscopy } \\
\hline Diagnostic & 531 & 22 & 11,682 & 283 & 150,273 \\
\hline Therapeutic & 603 & 2 & 1206 & 30 & 18,090 \\
\hline \multicolumn{6}{|l|}{ ERCP } \\
\hline Therapeutic & 3,136 & 17 & 53,312 & 99 & 310,464 \\
\hline Diagnostic & 1,124 & 0 & 0 & 11 & 12,364 \\
\hline \multicolumn{6}{|l|}{ EUS } \\
\hline Diagnostic & 839 & 9 & 7551 & 41 & 34,399 \\
\hline DBE & 3,008 & 4 & 12,032 & 32 & 96,256 \\
\hline Transnasal endoscopy & 547 & 1 & 547 & 4 & 2188 \\
\hline Total & & 230 & 195,264 & 3207 & $2,323,414$ \\
\hline
\end{tabular}

$\overline{D B E}$, double-balloon enteroscopy; ERCP, endoscopic retrograde cholangiopancreatography; EUS, endoscopic ultrasound 
protective equipment was supplied directly by the British government through emergency pandemic relief funding, thus reducing the additional burden of PPE cost per procedure.

\section{Discussion}

With over 7 million infected patients in over 200 countries/ regions globally to date, COVID-19 pandemic has radically changed our lives and the world we live in. The impact of COVID-19 on daily hospital activities was also unprecedented. In particular, during the peak of the COVID-19 pandemic many clinicians and nurses were redeployed to temporary COVID-19 wards, created ad hoc to manage this novel category of patients. Others were redeployed to the ICU to support anesthetist colleagues and nurses, since this area had become grossly understaffed in the face of the exponential wave of patients with COVID-19 requiring ventilation.

These extraordinary and urgent circumstances had indirectly, albeit just as gravely, affected the healthcare provision to other patients requiring "less urgent" and elective outpatient procedures. Outpatient appointments were broadly postponed and urgent face-to-face appointments (including those for patients on an urgent cancer pathway), were converted to telephone clinics. Elective, non-urgent surgical procedures were canceled, in order to avoid any additional burden on the ICU.

A similar strategy was adopted for all non-urgent/elective outpatient appointments for diagnostic/therapeutic medical procedures such as endoscopy and radiology. Only patients requiring urgent or non-deferrable medical attention were being investigated during this period. Because of this unforeseen situation, our endoscopy unit, like many others around the world, was initially forced to rapidly reduce the number of procedures, and consequently to cancel all non-urgent and elective procedures. This extreme strategy allowed our department to redeploy medical and nursing staff to where they were needed most, to enhance our response to the consequences of the pandemic.

Given that: (i) SARS-CoV-2 infection has been proven to be extremely contagious [2,3]; (ii) asymptomatic patients infected with SARS-CoV-2 are a large source of infection [4,5]; and (iii) the hospital is considered to be a high-risk site for infection acquisition, a further potential benefit of this strategy was to minimize the risk of nosocomial spread to patients and staff. Our results suggest that the magnitude of the effect of COVID-19 on endoscopy activity during the peak was very sizable. Our data demonstrate that there was an estimated reduction of endoscopic activity of an order of approximately 7 -fold for the "delay phase" as compared with the same timeframe in the previous year. The data relating to the "lockdown phase" are even more ominous, since they show an 11.8-fold reduction of the overall number procedures vis-à-vis 2019.

Undoubtedly, these extreme but necessary measures will have substantial repercussions for the welfare of our patients and the wider healthcare system. Once the initial burden of influx of COVID-19-related hospitalizations subsides, we are sure to face a huge backlog of cases postponed as a result of the first wave of this pandemic. We estimated that the number of lists required to

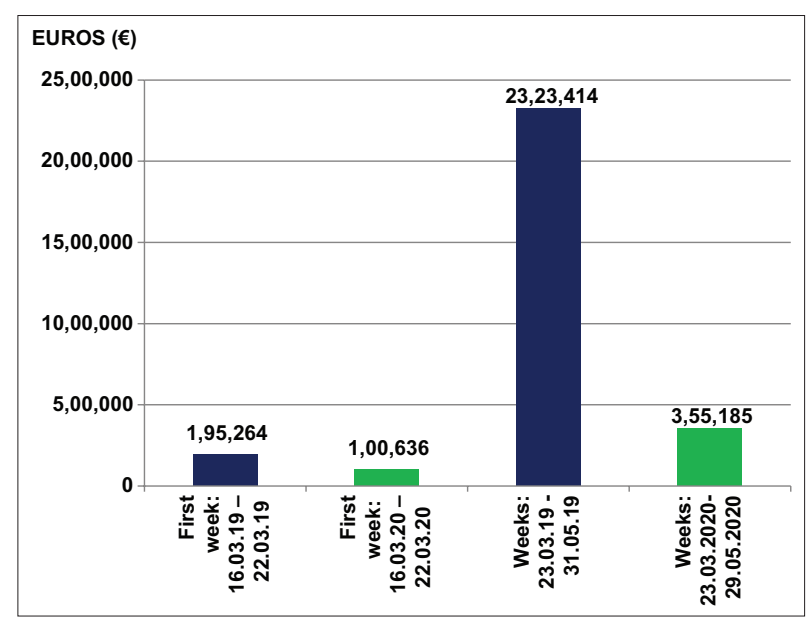

Figure 2 Revenue $(€)$ generated by the endoscopy unit during the delay and lockdown phases compared to the same period in 2019

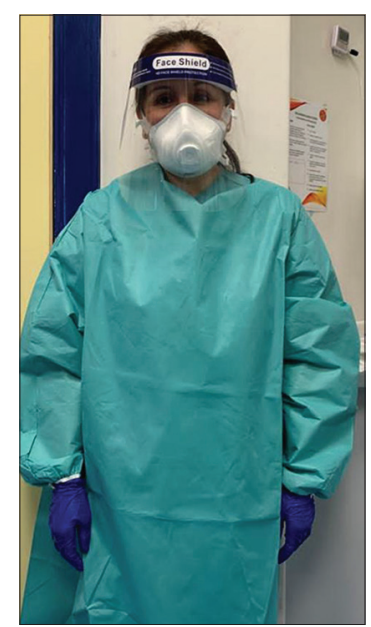

Figure 3 Personal protective equipment used in the endoscopy unit during the COVID-19 pandemic

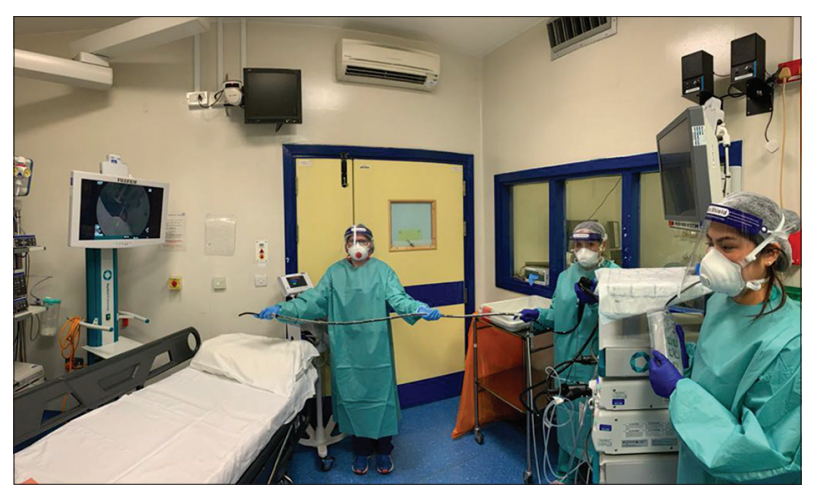

Figure 4 Setup of the endoscopy room during an anterograde doubleballoon enteroscopy at the Royal Free Hospital in London

recuperate the endoscopic activity canceled during the delay and the lockdown phases ranges from 103-155, depending on the PPE policy/perceived COVID-19 transmission risk, as described by Gupta et al [24]. We are also very likely to see a "domino 
effect" on delays/extension of waiting times for any new/ additional endoscopy procedures requested during and after the lockdown phase. In light of this, we believe that to reduce further delay in cancer diagnostics, careful vetting of procedure requests should be carried out for appropriate prioritization of higherrisk patients on suspected cancer pathways [26].

In addition, we showed that the impact of COVID-19 pandemic had also significant financial repercussions for our endoscopy unit. Our data suggest that during the delay and lockdown phase the economic revenue generated by the endoscopy was $€ 455,821$, whereas during the same timeframe in 2019 our endoscopy unit generated revenue of $€ 2,518,678$. Thus, the loss of profit due to COVID-19 for our endoscopy unit during the peak in the UK was $€ 2,062,857$. The magnitude of this deficit is likely to be compounded several-fold, when one considers that in an attempt to mitigate the backlog of postponed procedures, in addition to any new referrals, our system will be obliged to divert further financial resources to external medical services/providers and to cover financiallyincentivized extra lists worked by our own hospital staff.

In conclusion, the results of our study highlight that the COVID-19 pandemic had a considerable negative clinical and economic impact on our endoscopy service provision. Furthermore, analysis of our projected figures shows that the impact of the COVID-19 pandemic may have even more severe repercussions for future hospital activity and economics, as we aim to recuperate any canceled or postponed activity. In addition, the potential wide-ranging repercussions of delay in cancer care and other pathologies are still not fully understood, and studies to shed further light on them are required.

\section{Summary Box}

\section{What is already known:}

- COVID-19 is a highly infectious disease caused by the newly discovered SARS-CoV-2

- During the pandemic peak, national and international gastroenterology societies recommended that all elective and non-urgent endoscopic procedures should be postponed

- Little is known about the economic impact of the lockdown on endoscopy units

\section{What the new findings are:}

- Our results assess the magnitude of the effect of the COVID-19 pandemic on endoscopy activity

- The data suggest that during the delay and lockdown phases the economic revenue generated by the endoscopy unit was significantly reduced

- Endoscopy units need to plan ahead in order to promptly accommodate the backlog of cases postponed during the pandemic

- Evaluation of the financial repercussions for future hospital activity and economics should be further investigated

\section{References}

1. Chan JFW, Yuan S, Kok KH, et al. A familial cluster of pneumonia associated with the 2019 novel coronavirus indicating personto-person transmission: a study of a family cluster. Lancet 2020;395:514-523.

2. World Health Organization. Coronavirus disease (COVID-19) Situation Report 84. Geneva, Switzerland: WHO, 2020. Available from: https://www.who.int/docs/default-source/ coronaviruse/situation-reports/20200413-sitrep-84-covid-19. pdf?sfvrsn=44f511ab_2 [Accessed 26 May 2021].

3. World Health Organization. Coronavirus disease (COVID-2019) Situation Report 51. Geneva, Switzerland: WHO, 2020. Available from: https://www.who.int/docs/default-source/ coronaviruse/situation-reports/20200311-sitrep-51-covid-19. pdf?sfvrsn=1ba62e57_10 [Accessed 26 May 2021].

4. Bai Y, Yao L, Wei T, et al. Presumed asymptomatic carrier transmission of COVID-19. JAMA 2020;323:1406-1407.

5. Sutton D, Fuchs K, D’Alton $\mathrm{M}$, et al. Universal screening for SARS-CoV-2 in women admitted for delivery. $N$ Engl J Med 2020;382:2163-2164.

6. Repici A, Maselli R, Colombo M, et al. Coronavirus (COVID-19) outbreak: what the department of endoscopy should know. Gastrointest Endosc 2020;92:192-197.

7. Zhou F, Yu T, Du R, et al. Clinical course and risk factors for mortality of adult inpatients with COVID-19 in Wuhan, China: a retrospective cohort study. Lancet 2020;395:1054-1062.

8. Verity R, Okell LC, Dorigatti I, et al. Estimates of the severity of Coronavirus disease 2019: a model-based analysis. Lancet Infect Dis 2020;20:669-677.

9. World Health Organization. Coronavirus disease (COVID-2019) Situation Report 1. Geneva, Switzerland: WHO, 2020. Available from: https://www.who.int/docs/default-source/ coronaviruse/situation-reports/20200121-sitrep-1-2019-ncov. pdf?sfvrsn=20a99c10_4 [Accessed 26 May 2021].

10. del Rio C, Malani PN. COVID-19 - New insights on a rapidly changing epidemic. JAMA 2020;323:1339-1340.

11. Xiao F, Tang M, Zheng X, Liu Y, Li X, Shan H. Evidence for gastrointestinal infection of SARS-CoV-2. Gastroenterology 2020;158:1831-1833.e3.

12. Gu J, Han B, Wang J. COVID-19: gastrointestinal manifestations and potential fecal-oral transmission. Gastroenterology 2020;158:1518-1519.

13. van Doremalen N, Bushmaker T, Morris DH, et al. Aerosol and surface stability of SARS-CoV-2 as compared with SARS-CoV-1. N Engl J Med 2020;382:1564-1567.

14. Wang D, Hu B, Hu C, et al. Clinical characteristics of 138 hospitalized patients with 2019 novel coronavirus-infected pneumonia in Wuhan, China. JAMA 2020;323:1061-1069.

15. British Society of Gastroenterology (BSG). Endoscopy activity and COVID-19: BSG and JAG guidance. Available from: https://www. bsg.org.uk/covid-19-advice/endoscopy-activity-and-covid-19bsg-and-jag-guidance/[Accessed 26 May 2021].

16. British Society of Gastroenterology (BSG). GI endoscopy activity and COVID-19: next steps. Available from: https://www.bsg.org. uk/covid-19-advice/gi-endoscopy-activity-and-covid-19-nextsteps/[Accessed 26 May 2021].

17. Gralnek IM, Hassan C, Beilenhoff U, et al. ESGE and ESGENA position statement on gastrointestinal endoscopy and the COVID-19 pandemic. Endoscopy 2020;52:483-490.

18. Castro Filho EC, Castro R, Fernandes FF, Pereira G, Perazzo H. Gastrointestinal endoscopy during the COVID-19 pandemic: an updated review of guidelines and statements from international and national societies. Gastrointest Endosc 2020;92:440-445.

19. World Health Organization. Report of the WHO-China joint 
mission on coronavirus disease 2019 (COVID-19). Geneva, Switzerland: WHO, 2020. Available from: https://www.who.int/ docs/default-source/coronaviruse/who-china-joint-mission-oncovid-19-final-report.pdf [Accessed 26 May 2021].

20. United Kingdom government, Department of Health and Social Care. Policy paper. Coronavirus action plan: a guide to what you can expect across the UK. Available from: https://www.gov.uk/ government/publications/coronavirus-action-plan/coronavirusaction-plan-a-guide-to-what-you-can-expect-across-the-uk [Accessed 26 May 2021].

21. United Kingdom government, Department of Health and Social Care. Press release. COVID-19: government announces moving out of contain phase and into delay. Available from: https://www.gov. uk/government/news/covid-19-government-announces-movingout-of-contain-phase-and-into-delay [Accessed 26 May 2021].

22. Ferguson NM, Laydon D, Nedjati-Gilani G, et al. Impact of non-pharmaceutical interventions (NPIs) to reduce COVID-19 mortality and healthcare demand. Imperial College COVID-19
Response Team, London, March 2020. Available from: https:// www.imperial.ac.uk/media/imperial-college/medicine/sph/ ide/gida-fellowships/Imperial-College-COVID19-NPImodelling-16-03-2020.pdf [Accessed 26 May 2021].

23. United Kingdom government, Government. Speech. Prime Minister's statement on coronavirus (COVID-19): 23 March 2020. Available from: https://www.gov.uk/government/speeches/pmaddress-to-the-nation-on-coronavirus-23-march-2020 [Accessed 26 May 2021].

24. Gupta S, Shahidi N, Gilroy N, Rex DK, Burgess NG, Bourke MJ. Proposal for the return to routine endoscopy during the COVID-19 pandemic. Gastrointest Endosc 2020;92:735-742.

25. National Health Service (NHS). 2019/20 National Tariff Payment System. Available from: https://www.england.nhs.uk/publication/ past-national-tariff-documents-and-policies/[Accessed 26 May 2021].

26. Thompson MR. ACPGBI Referral guidelines for colorectal cancer. Colorectal Dis 2002;4:287-297. 